\title{
Fish Oil Supplementation in Pregnancy Modifies Neonatal Progenitors at Birth in Infants at Risk of Atopy
}

\author{
JUDAH A. DENBURG, HOLLY M. HATFIELD, MICHAEL M. CYR, LISA HAYES, \\ PATRICK G. HOLT, ROMA SEHMI, JANET A. DUNSTAN, AND SUSAN L. PRESCOTT
}

\begin{abstract}
Department of Medicine [J.A.De., H.M.H., M.M.C., L.H., R.S.], McMaster University, Hamilton, Ontario, L8N $3 Z 5$ Canada, Telethon Institute for Child Health Research and Centre for Child Health Research [P.G.H.], University of Western Australia, Perth, Western Australia 6872, School of Paediatrics and Child Health [J.A.Du., S.L.P.], University of Western Australia, Subiaco, Western Australia 6008
\end{abstract}

\begin{abstract}
Dietary n-3 polyunsaturated fatty acids (PUFA) may represent a mode of allergy prevention. Cord blood (CB) CD34 $4^{+}$ hemopoietic progenitors are altered in infants at risk of atopy. We therefore studied the effects of dietary n-3 PUFA supplementation during pregnancy on numbers and function of progenitors in neonates at high risk of atopy. In a double-blind study, atopic, pregnant women were randomized to receive fish oil capsules or placebo from 20 wk gestation until delivery. At birth, CB CD34 ${ }^{+}$ cells were isolated and analyzed by flow cytometry for expression of cytokine (IL-5R $\alpha$, IL-3R $\alpha$, granulocyte/macrophage colony-stimulating factor $\mathrm{R} \alpha$ ) or chemokine (CXCR4 and CCR3) receptors. $\mathrm{CB}$ cells were also cultured in methylcellulose assays for eosinophil/basophil colony-forming cells. At age $1 \mathrm{y}$, infants were clinically assessed for atopic symptoms and skin tests. Percentages of $\mathrm{CB} \mathrm{CD} 34^{+}$cell numbers were higher after n-3 PUFA than placebo. Co-expression of cytokine or chemokine receptors on CD34 cells was not altered by n-3 PUFA supplementation. However, there were significantly more IL-5responsive $\mathrm{CB}$ eosinophil/basophil colony forming units (Eo/B$\mathrm{CFU})$ in the fish oil, compared with the control, group. Overall,
\end{abstract}

\section{ABSTRACT}

there was a positive association between $\mathrm{CD} 34^{+}$cells and IL-5responsive $\mathrm{Eo} / \mathrm{B}-\mathrm{CFU}$ in $\mathrm{CB}$ and $1 \mathrm{y}$ clinical outcomes, including atopic dermatitis and wheeze. Dietary n-3 PUFA supplementation during pregnancy in atopic mothers alters infant cord blood hemopoietic progenitor phenotype. This may have an impact on development of atopic disease. (Pediatr Res 57: 276-281, 2005)

$\quad$ Abbreviations
AEDS, atopic eczema/dermatitis syndrome
CB, umbilical cord blood
DHA, docosahexaenoic acid
Eo/B-CFU, eosinophil/basophil colony forming units
EPA, eicosapentaenoic acid
GM-CSF, granulocyte/macrophage colony-stimulating factor
MNC, mononuclear cell
NAMNC, nonadherent mononuclear cell
n-3 PUFA, omega-3 polyunsaturated fatty acids
PE, phycoerythrin
SPT, skin prick test

Atopic disease is increasingly prevalent in developed countries, especially in childhood. This has been associated with many environmental changes altered by increasing urbanization such as diet, housing, infections, and pollution (1). The negative impact of atopic disease on quality of life, along with the high expense of long-term treatment of symptoms, necessitates implementation of better strategies for prevention and treatment. To attain these goals, it is imperative to further

Received April 13, 2004; accepted July 23, 2004.

Correspondence: Judah A. Denburg, M.D., FRCPC, Professor of Medicine, Director, Clinical Immunology and Allergy, HSC-3V46, McMaster University, 1200 Main Street West, Hamilton, ON L8N 3Z5, Canada, e-mail: denburg@mcmaster.ca

Supported by grants from the National Health and Medical Research Council and Raine Medical Research Foundation, Nedlands, Western Australia.

DOI: 10.1203/01.PDR.0000148279.72611.1D characterize mechanisms underlying the development of atopic disease and how these can be modified by environmental factors.

The characteristic IgE-mediated inflammation of atopic disease results from abnormalities in acquired immunity, involving inappropriate Th2 cytokine responses to ubiquitous environmental antigens (2). This contrasts with the normal Th1 cytokine pattern seen in nonallergic adults, although the factors leading to this apparent functional divergence in immune response remain unknown. Because allergen-specific immune responses develop in fetal life, maternal diet during pregnancy is an important factor, with the potential to influence the development of both acquired and innate immune responses that predispose toward atopy (3). n-3 PUFA, EPA (20:5n-3), and DHA (22:6n-3), found in oily fish, have multiple well- 
defined anti-inflammatory effects, and are promising candidates for atopic disease prevention (4-6). There is now a recognized need for studies to investigate the potential of dietary n-3 PUFA to modify early immune development.

Innate immunity, effected principally by myeloid inflammatory cells such as eosinophils, basophils, and mast cells, which characteristically differentiate and accumulate during the allergic response (7), may also be altered during the development of the atopic diathesis. We have demonstrated that the number of bone marrow-derived myeloid, IL-5-responsive progenitors is increased in atopic compared with normal control subjects (8). Using antibodies to a hemopoietic progenitor membrane protein marker, CD34, and to hemopoietic cytokine receptors, we have demonstrated alterations relevant to eosinophil/basophil lineage commitment of progenitors in neonates at risk for atopy (9).

In this study, we investigated the effects of maternal n-3 PUFA dietary supplementation in pregnancy on the characteristics of $\mathrm{CB}$ progenitor populations in infants at high risk of allergy. We measured differentiation profiles of $\mathrm{CD}^{+} 4^{+}$progenitors in $\mathrm{CB}$ in an attempt to characterize differences in hemopoietic responses that may predict atopy later in life. We hypothesized that n-3 PUFA supplementation of atopic mothers during pregnancy would have an effect on the number of $\mathrm{CB} \mathrm{CD} 34^{+}$progenitor cells, their surface expression of cytokine and chemokine receptors, and functional responsiveness to hemopoietic cytokines, and that these parameters would be related to the subsequent development of atopic features in later infancy.

\section{METHODS}

Study design. The effects of maternal n-3 PUFA dietary supplementation on neonatal $\mathrm{CD} 34^{+}$progenitor populations were determined using a double-blind, placebo-controlled study design.

Pregnant women with confirmed allergy [see Dunstan et al. (10)] were randomized at $20 \mathrm{wk}$ gestation to receive either fish oil capsules $(n=52)$ containing 3.7 g of n-3 PUFA (56\% DHA, 27.7\% EPA) or placebo $(n=46)$, olive oil capsules containing an amount $(2.6 \mathrm{~g})$ that did not significantly alter the daily average intake of oleic acid $(26 \mathrm{~g} / \mathrm{d})$. The supplements were taken daily for the remaining duration of the pregnancy, and the dose was approximately equivalent to one fish meal per day (11). At birth, CB was collected to assess neonatal immune function (see below). Although the fish oil capsules were well tolerated by the majority of the volunteers, seven women suffering from pregnancy-related "morning sickness" withdrew from the study because of "fishy burps." It was found that this could be minimized by having the capsules before food or with a cold drink.

Although the main objective of this study was to assess the effects of the intervention on neonatal immune outcomes (with the power calculations and samples size determined accordingly), the infants were also assessed clinically during the first year of life for potential adverse effects and atopic features. Thus, although these clinical outcomes are reported here, this was not the prime objective of this study, as a much larger population would be needed to address this issue.

Subjects. Ninety-eight atopic, pregnant women $(n=98)$ booked for delivery at St. John of God Hospital, Subiaco, WA, Australia (between January 1999 and September 2001) were recruited to the study. Women were defined as allergic if they had a history of doctor-diagnosed allergic rhinitis and/or asthma and one or more positive SPT to common allergens (house dust mite, grasses, moulds, cat, dog, feathers, and cockroach; Hollister-Stier Laboratories, Spokane, WA). A wheal size of $1>3 \mathrm{~mm}$ above the negative control was considered positive. This atopic population was selected because their unborn children were considered at high risk of developing atopic disease $(12,13)$.
Women were ineligible for the study if they smoked, had other medical problems, complicated pregnancies, seafood allergy, or their normal dietary intake exceeded two meals of fish per week.

Materials. Materials were obtained as follows: Iscove's modified Dulbecco's medium, FCS, RPMI medium 1640 from GIBCO (Burlington, ON, Canada); methylcellulose, BSA, sodium azide, paraformaldehyde from Sigma Chemical Co. Aldrich Ltd. (Oakville, ON, Canada); recombinant human cytokines GM-CSF, IL-3, and IL-5 from BD Biosciences (Mississauga, ON, Canada).

Cell isolation and cryopreservation. $\mathrm{CB}$ was collected at delivery, as previously described (10), into an equivolume of RPMI (GIBCO) plus heparin (Sigma Chemical Co. Aldrich Ltd) (the volume collected ranged from 5 to 120 $\mathrm{mL}$ depending on the condition of the placenta). MNC were isolated using Lymphoprep (Nycomed Pharma, Asker, Norway) gradient centrifugation at $500 \mathrm{~g}$ for $30 \mathrm{~min}$ and washed twice in RPMI and then once in RPMI containing $2 \%$ FCS (GIBCO). Cells were enumerated using a hemocytometer (improved Neubauer hemocytometer, Weber Scientific, West Sussex, England) and diluted to $40 \times 10^{6}$ cells $/ \mathrm{mL} \mathrm{RPMI} / 2 \% \mathrm{FCS}$ and placed on ice. An equal amount of cooled 15\% DMSO (BDH, Kilsyth, VIC, Australia) in FCS (MultiSer, BioSciences Pty. Ltd., Thebarton SA, Australia) was added dropwise. Samples were frozen in $1 \mathrm{~mL}$ aliquots each containing $20 \times 10^{6}$ cells, an optimal amount for freezing. The samples were cooled to $-80^{\circ} \mathrm{C}$ at a rate of $1^{\circ} \mathrm{C} / \mathrm{min}$ in a freezing container (Nalgene cryocontainer) containing isopropyl alcohol (BDH) and transferred to a liquid nitrogen tank for storage and shipment. It has been shown previously (by this laboratory and others) that cryopreservation and thawing does not distort cellular immune responses (14-16), including functional and phenotypic characteristics of $\mathrm{CD}_{3} 4^{+}$progenitor cells. MNC stored in liquid nitrogen $\left(2 \times 10^{7} \mathrm{CB}\right.$ MNC per patient) were transported from Australia to Canada. Cells were thawed by drop-wise application of $10 \%$ FCS, $1 \%$ penicillin/streptomycin, and 2.5\% HEPES buffer in RPMI medium 1640 (GIBCO), and resuspended in McCoy's $3+$ media (GIBCO), and incubated for $2 \mathrm{~h}$ in a plastic flask to remove adherent $\mathrm{MNC}\left(37^{\circ} \mathrm{C}, 5 \% \mathrm{CO}_{2}\right)$. NAMNC were then resuspended in $1 \mathrm{~mL}$ Iscove's $2+$ culture medium (GIBCO) and a cell count was performed. Average viability was $>98 \%$ and average NAMNC recovery was $48.5 \%$ of the total number of cells frozen (data not shown).

Methylcellulose cultures for assessing functional responsiveness to hemopoietic cytokines. NAMNC $\left(2 \times 10^{5}\right.$ cells $)$ were cultured in semisolid methylcellulose (Sigma Chemical Co. Aldrich), FCS, and Iscove's $2+$ in the presence of recombinant human cytokines IL-5, IL-3, or GM-CSF (all from BD Biosciences, ON, Canada), or equal amounts of Iscove's $2+$ as a control. Cultures were performed in duplicate and incubated for $14 \mathrm{~d}\left(37^{\circ} \mathrm{C}, 5 \% \mathrm{CO}_{2}\right)$. Mean numbers of Eo/B-CFU were enumerated from duplicate cultures using inverted light microscopy (colonies were defined as $>40$ cells) (17).

Antibodies. PE-conjugated IgG1, CD34 antibody (HPCA-2), FITCconjugated IgG1 CD45 antibody (anti-HLE1), PE-conjugated isotype control antibody (mouse IgG1), streptavidin PerCp, biotin anti-human GM-CSF receptor $\alpha$-chain (CD116), biotin anti-human CDw123 IL-3 receptor $\alpha$-chain, and biotin anti-human CXCR4 (fusin) were purchased from BD Pharmingen (Mississauga, ON, Canada). Anti-human CCR3 was purchased from R \& D Systems (Minneapolis, MN). Anti-human IL-5 receptor $\alpha$-chain was a gift from Roche Laboratories (Ghent, Belgium) and was biotinylated in our laboratory as previously described (18).

Flow cytometry for the enumeration of $\mathrm{CD}^{+} 4^{+}$progenitor cells and surface expression of cytokine and chemokine receptors. To enumerate $\mathrm{CD} 34^{+}$cells by flow cytometry, we used an established multiparameter gating strategy (19) and a three-color staining protocol to assess expression of cytokine receptors IL-5R $\alpha, \operatorname{IL} 3 \mathrm{R} \alpha$, and GM-CSFR $\alpha$ (8) as well as chemokine receptors CXCR4 and CCR3. Briefly, 2-5 $\times 10^{5}$ cells were stained with antibodies PE-conjugated CD34 (HPCA-2), FITC-conjugated CD45 (antiHLE1), PE-labelled isotype control (IgG1), and non-neutralizing MAb for IL-3R $\alpha, \mathrm{IL}-5 \mathrm{R} \alpha, \mathrm{GM}-\mathrm{CSFR} \alpha, \mathrm{CCR} 3$, and CXCR4. Acquisition was performed using a FACScan flow cytometer (BD Biosciences). At least $4 \times 10^{4}$ cells were collected for analysis. Analysis of receptor expression on CD $34^{+}$ cells by mean fluorescence intensity was not possible in this study due to low numbers of cells available in each sample. Although the cell population being assessed is rare, the low percentages of receptor expression on these cells is valid using the gating strategy $(18,19)$. WinList software (Verity Software House, Topsham, ME) was used for analysis of data. 
Clinical assessment of atopic disease. Although clinical outcomes were not a prime objective of the study, infants were clinically evaluated at 12 mo of age by a pediatric allergist and immunologist (S.L.P.), who remained blind to the randomization. The main clinical outcomes assessed are defined in Dunstan et al. (20). In brief, clinical outcomes were the presence or absence of wheeze, AEDS, and allergen skin test reactivity. An SPT was performed using a standardized technique (14) and allergen extracts (egg, milk, peanut, house dust mite, cat) (Hollister-Stier Laboratories) as well as histamine as a positive control and glycerine as a negative control. A wheal diameter of $\geq 2 \mathrm{~mm}$ was considered positive.

Statistical analysis. All statistical analyses were performed using SPSS software (Version 10 for Macintosh, SPSS Inc., Chicago, IL). Differences between the intervention and placebo group were determined by $t$ test for normally distributed interval data and the Pearson $\chi^{2}$ test for categorical data. Interval data were found to be normally distributed using the KolmogorovSmirnov and Shapiro-Wilk statistic.

Relationships between continuous variables were determined by Pearson correlation and expressed as the correlation coefficient $(r)$. Relationships between continuous or categorical independent variables and binary outcome dependent variables were analyzed using logistic regression and were described by odds ratio $(\mathrm{OR})$ and $95 \%$ confidence interval $(\mathrm{CI})$. There were no potential confounding factors as determined by Pearson correlation. Factors tested included duration of gestation, parity, infant gender, and method of delivery. A $p$ value $<0.05$ was considered statistically significant for all planned analyses.

Ethics approval. Ethical approval for the study was granted by the Princess Margaret Hospital for Children, the King Edward Memorial Hospital, and the St. John of God Hospital, Subiaco, ethics committees. All subjects signed written consent.

\section{RESULTS}

Subjects. Of the 98 randomized subjects, 83 mothers and infants completed the study up to $1 \mathrm{y}$ follow-up postpartum (10). At delivery, 40 infant CB samples were analyzed from the fish oil-treated group and 43 from the control group. Reasons for study discontinuation included maternal nausea (fish oil, $n$ = 7; control, $n=1$ ), $\mathrm{CB}$ not collected (control, $n=1$ ), gestation $<36$ wk (fish oil, $n=3$; control, $n=1$ ), or infant disease (fish oil, $n=2$ ). Sample processing during freezing and thawing resulted in the loss of several samples or reduced yield, accounting for the lower $n$ numbers in the assays (see below). There were no significant differences detected in baseline characteristics of subjects that completed the study in the fish oil group compared with those in the control group, nor were there any differences detected in characteristics of the neonates [not shown, refer to Dunstan et al. (10)].

CB progenitor colony assays. Using a previously described clonogenic assay, responsiveness of progenitor cells to cytokines that induce eosinophilic differentiation was quantified (21). The number of Eo/B-CFU per $2 \times 10^{5}$ NAMNC plated was enumerated; values represent the mean \pm SEM of duplicate cultures of $n=27$ in the fish oil group and $n=29$ in the control group. There was no significant difference in the number of Eo/B-CFU grown in the presence of IL-3 or GM-CSF between groups (Fig. 1). However, there was a significant increase in $\mathrm{CB} \mathrm{Eo} / \mathrm{B}-\mathrm{CFU}$, grown in the presence of IL-5, in neonates in the n-3 PUFA supplementation group compared with the placebo group $(12.43 \pm 1.34$ versus $8.19 \pm 1.15, p<$ 0.03 , Fig. 1).

CB progenitor flow cytometric analyses. The numbers of $\mathrm{CB}$-derived $\mathrm{CD} 34^{+}$progenitor cells and percentage of $\mathrm{CD} 34^{+}$ cells expressing IL-5R $\alpha, \mathrm{IL}-3 \mathrm{R} \alpha, \mathrm{GM}-\mathrm{CSFR} \alpha, \mathrm{CCR} 3$, and
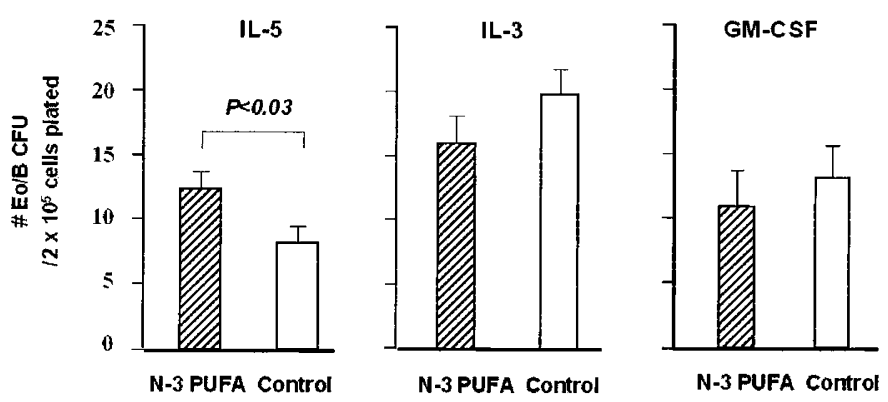

Figure 1. Number of Eo/B-CFU grown in the presence of $(A)$ recombinant human $(\mathrm{rh}) \mathrm{IL}-5(1 \mathrm{ng} / \mathrm{mL})(p<0.03),(B)$ rhIL-3 $(1 \mathrm{ng} / \mathrm{mL})$, and $(C)$ rhGM-CSF (10 ng/mL). PUFA group, $n=27$; controls, $n=29$. Bars represent mean \pm SEM.

CXCR4 were assessed by multiparameter flow cytometric analysis. In the fish oil supplementation group $(n=31)$, the percentage of CB-derived CD $34^{+}$cells was higher than in the control group $(n=29 ; 0.879 \pm 0.096 \%$ versus $0.533 \pm$ $0.041 \%, p<0.002$ ) (Fig. 2). There was no significant difference in cytokine or chemokine receptor expression on $\mathrm{CB}$ $\mathrm{CD} 34^{+}$cells between groups (Table 1).

When the number of IL-5-responsive CB Eo/B-CFU was correlated with the percentage of $\mathrm{CD} 34^{+} / 45^{+}$cells, a significant relationship was found overall, as well as for the PUFA group ( $r=0.655, p<0.001, n=29)$, but not for the control group ( $r=0.340, p>0.05, n=25$ ) (Fig. 3). Also, for the combined groups, we observed a negative association overall between IL-5R $\alpha$ and GM-CSFR $\alpha$ (Fig. 4) or IL-5R $\alpha$ alone (not shown) on $\mathrm{CD} 34^{+}$cells with maternal atopic risk (measured by number of positive SPT) $(r=-0.270, p<0.04 ; r=$

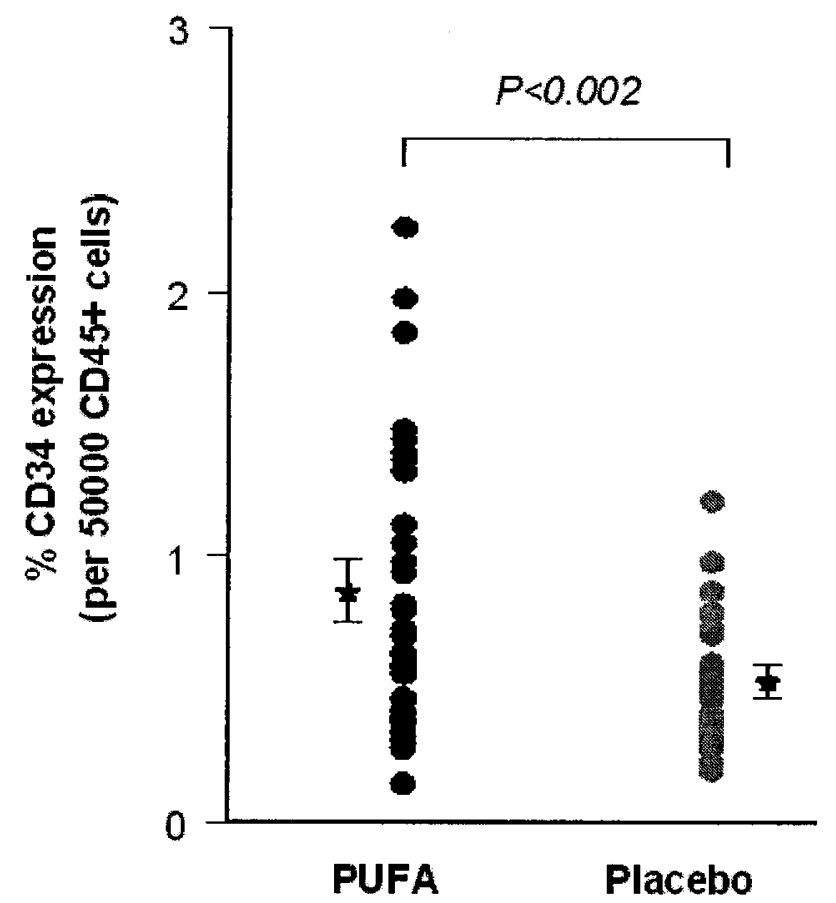

Figure 2. Percentage CD34 expression on $\mathrm{CD} 45^{+} \mathrm{MNC}$ is increased in $\mathrm{CB}$ from neonates of mothers supplemented with n-3 PUFA during pregnancy. PUFA group, $n=31$; controls, $n=29, p<0.002$. Bars represent mean \pm SEM. 
Table 1. Expression of cytokine and chemokine receptors on CD $34^{+} \mathrm{CD}_{4} 5^{+}$cells in cord blood of neonates of women supplemented with n-3 PUFA compared with those from women supplemented with olive oil (control)*

\begin{tabular}{lccc}
\hline \multicolumn{1}{c}{ Receptor } & $\begin{array}{c}\mathrm{n}-3 \text { PUFA mean } \\
\text { expression } \\
\left(\%^{*} \pm \mathrm{SD}\right)\end{array}$ & $\begin{array}{c}\text { Placebo mean } \\
\text { expression } \\
\left(\%^{*} \pm \mathrm{SD}\right)\end{array}$ & $\begin{array}{c}t \text { test } \\
\text { (unpaired, equal variance) }\end{array}$ \\
\hline IL-3R $\alpha$ & $4.628 \pm 3.366$ & $5.346 \pm 4.804$ & $p=0.498$ \\
IL-5R $\alpha$ & $0.816 \pm 1.152$ & $0.645 \pm 0.980$ & $p=0.537$ \\
GM-CSFR $\alpha$ & $1.941 \pm 2.319$ & $1.378 \pm 1.882$ & $p=0.305$ \\
CXCR4 & $4.314 \pm 3.250$ & $2.974 \pm 3.348$ & $p=0.118$ \\
CCR3 & $0.938 \pm 2.292$ & $1.091 \pm 1.634$ & $p=0.773$ \\
\hline
\end{tabular}

* Receptor expression (percentage expressed on $\mathrm{CD} 34^{+} \mathrm{CD} 45^{+}$cells) as measured by flow cytometry. Expression of all cytokine and chemokine receptors did not differ significantly between groups as determined by unpaired student's $t$ test. Statistical significance was assumed at $p<0.05$.

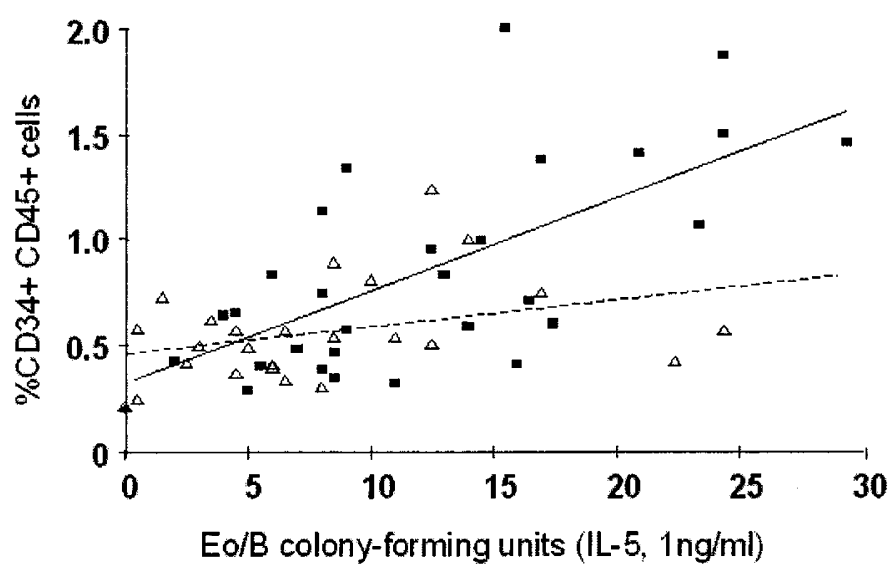

Figure 3. Association between percentage of $\mathrm{CD} 34^{+} \mathrm{CD} 45^{+}$cells with number of Eo/B-CFU grown in the presence of IL-5. Solid squares represent the PUFA group and the solid line shows the regression: ${ }^{*} r=0.655, p<$ $0.001, n=29$. The open triangles represent the olive oil group and the dashed line presents the regression: $r=0.340$, not significant, $n=25$. *Pearson's correlation coefficient.

$-0.259, p<0.05 ; \mathrm{IL}-5 \mathrm{R} \alpha / \mathrm{GM}-\mathrm{CSFR} \alpha$ and IL-5R $\alpha$ alone, respectively). In analyses for each treatment group separately, no significance was found.

Preliminary clinical outcomes at 1 y: relation to progenitor data. Although the study was not statistically powered to look at the effects of the dietary outcomes on clinical outcomes, we have previously noted (20) that infants in the fish oil group ( $n$ $=40$ ) were three times less likely to have a positive SPT to egg at $1 \mathrm{y}$ of age (OR $=0.34,95 \%$ CI: $0.11-1.02, p=0.055)$ than those in the control group $(n=43)$. Although there was no significant difference in the frequency of AEDS at $1 \mathrm{y}$ of age ( $n$ $=13$ in the fish oil group and $n=18$ in the control group; OR $=1.89,95 \%$ CI: $0.77-4.65, p=0.167)$, infants in the fish oil group had significantly less severe AEDS (OR $=0.09,95 \%$ CI: $0.01-0.94, p=0.045$ ).

From the 1 y preliminary clinical data, there were some associations with the progenitor data at birth. In this study, when the groups were combined $(n=60)$, we observed that the percentage of $\mathrm{CD} 34^{+}$cells $(\mathrm{OR}=3.93,95 \%$ CI: $1.05-14.64$, $p=0.042)$, and the number of IL-5-responsive Eo/B-CFU (OR $=1.09,95 \%$ CI: $1.004-1.184, p=0.039)$ in CB positively predicted atopic dermatitis at age $12 \mathrm{mo}$ (Table 2). The number

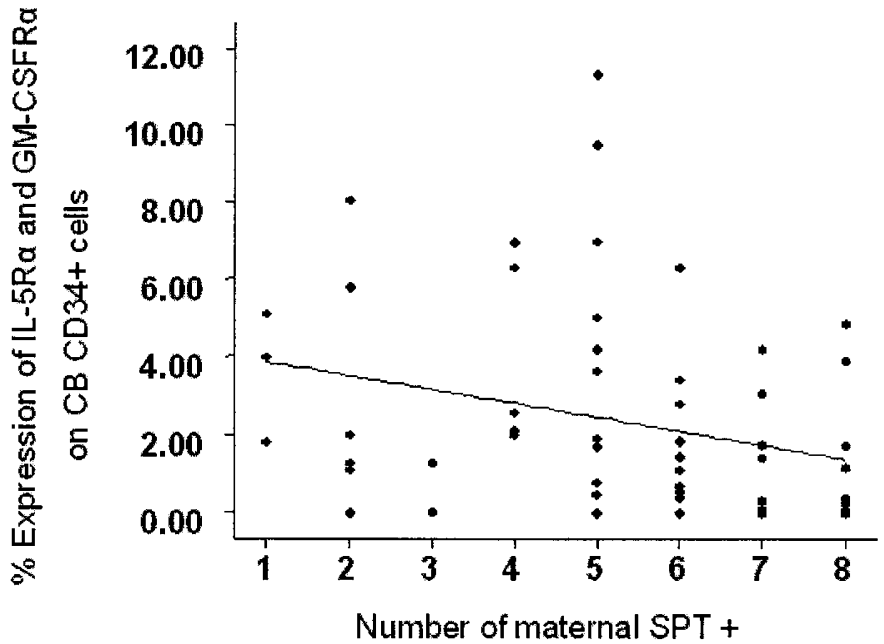

Figure 4. Negative association between the number of maternal positive allergen skin tests and neonatal $\mathrm{CB} \mathrm{CD} 34^{+}$progenitor expression of IL-5R $\alpha$ and GM-CSFR $\alpha .{ }^{*} r=-0.270, p<0.04, n=59$. *Pearson's correlation coefficient.

of IL-5-responsive Eo/B-CFU also positively predicted wheeze at $1 \mathrm{y}(\mathrm{OR}=1.107,95 \% \mathrm{CI}: 1.015-1.208, p=0.022)$ (Table 2). There was no association between the percentage of $\mathrm{CD} 34^{+}$ cells or the number of IL-5-responsive Eo/B-CFU and all other clinical outcomes at $1 \mathrm{y}$ (Table 2).

\section{DISCUSSION}

This study confirms that maternal dietary supplementation, which effectively increased n-3 PUFA levels in neonatal cell membranes (10), has significant effects on $\mathrm{CD} 34^{+}$progenitor populations in $\mathrm{CB}$. Although we have previously noted that maternal dietary n-3 PUFA can alter neonatal "cognate" lymphocyte function (10), this is the first report that maternal n-3 PUFA also have the capacity to alter CB progenitor populations critical for the development of innate immunity: i.e. myeloid progenitors for inflammatory cells (eosinophils, basophils) that favor the development of allergic disease. Maternal supplementation with n-3 PUFA during pregnancy was associated with increased numbers of $\mathrm{CD} 34^{+}$cells in neonatal CB (Fig. 2). Although there was no difference in the expression of IL-5R on $\mathrm{CD} 34^{+}$cells compared with the control group (Table 1), neonates in the fish oil group showed increased progenitor responsiveness to IL-5 in the functional culture assay (Fig. 1).

Although the anti-inflammatory effects of n-3 PUFA are well described both in vivo and in vitro (22), the exact mechanisms are unclear. Dietary fish oil supplementation has been previously associated with down-regulation of many aspects of the immune response, including diminished antigen presentation (23), cytokine receptor expression (24), lymphoproliferation (25-27), and cytokine responses, as recently reviewed in detail by Calder et al. $(22,28,29)$. The mechanisms of these effects are complex but may be, in part, due to competitive inhibition of the n-6 PUFA derived inflammatory eicosanoids [such as prostaglandin E2 (PGE2), thromboxane (TX), and the series-4 leukotrienes (LTB4, LTC4, LTD4)] and production of 
Table 2. Associations (odds ratios) between (A) clinical outcomes (at age 1 y in all infants) and cord blood CD34 ${ }^{+}$cells (\%), and (B) clinical outcomes (at age 1 y in all infants) and cord blood progenitor responsiveness to IL-5*

\begin{tabular}{|c|c|c|c|c|c|c|}
\hline \multirow[b]{3}{*}{ Clinical outcome } & \multicolumn{3}{|c|}{ A } & \multicolumn{3}{|c|}{$\mathrm{B}$} \\
\hline & \multicolumn{3}{|c|}{$\mathrm{CD}_{3} 4^{+}$cells in $\mathrm{CB}$} & \multicolumn{3}{|c|}{ Progenitor IL-5 responsiveness } \\
\hline & Odds ratio & $95 \% \mathrm{CI}$ & $p$ Value & Odds ratio & $95 \% \mathrm{CI}$ & $p$ Value \\
\hline Food allergy & 0.86 & $0.10-7.53$ & 0.892 & 0.997 & $0.88-1.13$ & 0.957 \\
\hline AEDS & 3.93 & $1.05-14.64$ & $0.042 \dagger$ & 1.09 & $1.00-1.18$ & $0.039 \dagger$ \\
\hline Moderate severe AEDS & 1.28 & $0.15-11.33$ & 0.822 & 0.93 & $0.80-1.08$ & 0.327 \\
\hline Asthma & 0.70 & $0.11-4.49$ & 0.710 & 0.98 & $0.87-1.10$ & 0.720 \\
\hline Chronic cough & 0.67 & $0.15-3.08$ & 0.610 & 0.96 & $0.87-1.06$ & 0.404 \\
\hline Recurrent wheeze & 1.47 & $0.42-5.20$ & 0.547 & 1.11 & $1.02-1.21$ & $0.022 \dagger$ \\
\hline
\end{tabular}

* There were no statistically significant associations between either percentage of CD34 ${ }^{+}$cells in CB or progenitor IL-5 responsiveness and the following clinical outcomes measured at $1 \mathrm{y}$ : anaphylaxis, acute angioedema, any $\mathrm{SPT}^{+}$or $\mathrm{SPT}^{+}$to specific allergens (egg, peanut, cow's milk, house dust mite, or cat). $\dagger$ Significant at $p<0.05$.

less inflammatory prostaglandins and leukotrienes such as $\mathrm{PGE}_{3}$ and $\mathrm{LTB}_{5}$ (30). The mechanism of the observed effect of n-3 PUFA maternal dietary supplementation on numbers of $\mathrm{CD} 4^{+}$cells in $\mathrm{CB}$ in this study remains unclear. It is possible that by altering the phospholipid membrane structure of cells (4), n-3 PUFA may directly modulate the expression of CD34 on progenitor cells. It is also possible that n-3 PUFA may directly or indirectly affect either production or trafficking of CD $34^{+}$progenitor cells. The lack of significant effect of PUFA on $\mathrm{CD} 34^{+}$cell cytokine or chemokine receptor phenotypes ex vivo may relate to mobilisation by $\mathrm{PUFA}$ into $\mathrm{CB}$ of more immature $\mathrm{CD}_{3} 4^{+}$progenitor populations.

The reason for the increase in IL-5 responsiveness of eosinophil progenitors in $\mathrm{CB}$ from neonates in the fish oil group, without a concomitant increase in IL-5 receptor expression, may relate to differences between these two hemopoietic assays: the colony assay detects progenitor cells that show proliferative and differentiative responses to cytokines, whereas the flow cytometric assay simply quantitates total numbers of progenitor cells bearing detectable numbers of cytokine receptors, without regard to proliferative or differentiative response. Inasmuch as the numbers of IL-5 receptors per cell (by mean fluorescence intensity) could not be assessed by flow cytometry in this study due to low numbers of cells available for each sample, a few cells with very-high-density receptors could account for the enhanced functional IL-5 responsiveness observed in the colony assay. The study was double-blinded and data were analyzed after the assays were complete; thus, it was not possible to assess the data by mean fluorescence intensity posthoc as there were limited cells in each sample. It is also possible that the increased IL-5 responsiveness of $\mathrm{CD}_{3} 4^{+}$cells in the n-3 PUFA supplement group is due to in vivo/in vitro changes in progenitor eicosanoid production or responsiveness, leading to a synergistic effect of IL-5 with cysteinyl leukotrienes, as we have recently demonstrated $(31,32)$; alternatively, changes in eicosanoids in vivo or in vitro may lead to altered progenitor cell trafficking in $\mathrm{CB}$. Our findings show a positive correlation between IL-5responsive $\mathrm{CFU}$ and absolute numbers of $\mathrm{CD} 34^{+} / 45^{+}$cells, similar to the correlation established by Sehmi et al. (8). This supports the concept that estimations of $\mathrm{CD} 34^{+} / 45^{+}$cells, by flow cytometry, are predictive of the colony-forming capacity in response to IL-5.
Atopic risk has been shown to be associated with downregulation of both cytokine responsiveness and production by CB NAMNC $(33,34)$. This appears to be at odds with our current findings of increased numbers of $\mathrm{CD}_{3} 4^{+}$progenitors and their increased responsiveness to IL-5 in CB. However, the current finding of an association between down-regulation of GM-CSFR $\alpha$ and IL-5R $\alpha$ and high maternal atopic risk agrees with our previous findings (9) and our newly acquired data relating maternal SPT and CB progenitor expression of GMCSFR $\alpha$ and IL-5R $\alpha$ (unpublished data). Thus, both suggest a complexity in the relationship between $\mathrm{CB}$ progenitors and atopic risk; for example, the n-3 PUFA manipulation, which lowers risk of atopic symptoms at $1 \mathrm{y}$ (20), may enhance the progenitors' functional differentiative profile (as we have shown), at least temporarily. This may be related to the hypothesis that infants at risk of atopy have a delayed immune maturation. Because the n-3 PUFA treatment increased the IL-5 responsiveness of $\mathrm{CD}_{3} 4^{+}$progenitors, effectively, this means that these cells were more mature at birth. This is possibly a result of the n-3 PUFA intervention and is reaffirmed by the finding that infants in the fish oil group generally had fewer atopic symptoms at $1 \mathrm{y}$ than at-risk infants in the placebo group.

Overall, the IL-5 responsive Eo/B-CFU prediction of firstyear outcomes may be indicative of a postnatal maturation of CD34/45 cells in vivo into IL-5 responsive CFU cells. The negative overall association between IL-5R $\alpha$ or IL-5R $\alpha / \mathrm{GM}$ CSFR $\alpha$ and maternal skin test positivity at birth (Fig. 4) also supports the concept of immaturity of eosinophil progenitor phenotype in at-risk infants at birth. We speculate that the IL-5 responsiveness in vitro mimics IL-5 stimulation in vivo, and that maturation of eosinophil progenitors will positively correlate with increasing atopy through childhood.

The main limitation of the study is the sample size, because this primarily represents an exploratory study to assess possible immunologic factors to be assessed in larger scale studies of n-3 PUFA for allergy prevention. In this regard, clinical allergic disease at $1 \mathrm{y}$ was only a secondary outcome of the current study; the difficulties of diagnosing allergy and asthma at this age are well recognized. Further analysis at 2.5 and 5 y of age will provide a more reliable assessment of such clinical outcomes. Other potential limitations include the effects of confounding factors such as age, body mass index, parity, and 
allergy status. Although these factors were controlled for by the use of block randomization and strict exclusion criteria (maternal smoking, premature birth, and existing disease), it is possible that as-yet-undetermined factors may have had an effect on our outcome measures. Despite these limitations, a number of immunologically significant observations were made, indicating that modification of maternal diet in pregnancy can have effects on the neonatal immune system.

Thus, although the study was not powered to examine the impact of the maternal dietary n-3 PUFA on infant allergy, we did observe a significant association in the entire cohort (note: only 60 of the $83 \mathrm{CB}$ samples were tested) between the number of IL-5-responsive eosinophil-basophil lineage committed progenitors in CB and subsequent atopic features. The number of IL-5-responsive progenitors positively predicted atopic dermatitis and wheeze at $1 \mathrm{y}(\mathrm{OR}=1.09,95 \% \mathrm{CI}: 1.004-1.184, p=$ 0.039 and $\mathrm{OR}=1.107,95 \% \mathrm{CI}: 1.015-1.208, p=0.022$, respectively). Also, the percentage of $\mathrm{CD} 34^{+}$cells positively predicted atopic dermatitis at age $1 \mathrm{y}(\mathrm{OR}=3.93,95 \% \mathrm{CI}$ : 1.05-14.64, $p=0.042$ ) (Table 2). These are preliminary associations and the study is ongoing; unfortunately, results beyond $1 \mathrm{y}$ are not yet available. Nevertheless, these findings, although early, highlight the possibility that effects on progenitors at birth by n-3 PUFA supplementation during pregnancy may result in clinically relevant changes.

The findings of this study suggest that detectable variations in the characteristics of hemopoietic cells in CB may be associated with the development of subsequent allergic disease and contribute to our understanding of the early immunologic events in neonates at risk of developing allergic disease. There are already cells in the $\mathrm{CB}$ at birth, which are progenitors or effector cells of the allergic late phase reaction, despite the fact that symptoms do not develop until much later. Furthermore, our observations provide preliminary evidence that dietary fish oil supplementation can modify the characteristics of these eosinophil-basophil progenitors at birth. Larger studies are clearly needed to confirm the suggestive benefits of n-3 PUFA in reducing the risk of subsequent allergic disease, through this and other immunologic pathways.

Acknowledgments. The authors thank the staff and volunteers who assisted with this study. We also thank the obstetricians and midwives at St. John of God Hospital, Subiaco, Western Australia.

\section{REFERENCES}

1. Strachan DP 1989 Hay fever, hygiene, and household size. BMJ 299:1259-1260

2. Holt PG, Macaubas C, Stumbles PA, Sly PD 1999 The role of allergy in the development of asthma. Nature 402:B12-B17

3. Prescott SL, Macaubas C, Holt BJ, Smallacombe TB, Loh R, Sly PD, Holt PG 1998 Transplacental priming of the human immune system to environmental allergens: universal skewing of initial $\mathrm{T}$ cell responses toward the Th2 cytokine profile. J Immunol 160:4730-4737

4. Purasiri P, Mckechnie A, Heys SD, Eremin O 1997 Modulation in vitro of human natural cytotoxicity, lymphocyte proliferative response to mitogens and cytokine production by essential fatty acids. Immunology 92:166-172

5. Calder PC, Miles EA 2000 Fatty acids and atopic disease. Pediatr Allergy Immunol 11(suppl 13):29-36
6. Soyland E, Nenseter MS, Braathen L, Drevon CA 1993 Very long chain n-3 and n-6 polyunsaturated fatty acids inhibit proliferation of human T-lymphocytes in vitro. Eur J Clin Invest 23:112-121

7. Denburg JA 1991 Basophils, mast cells and eosinophils and their precursors in allergic rhinitis. Clin Exp Allergy 21:253-258

8. Sehmi R, Howie K, Sutherland DR, Schragge W, O’Byrne PM, Denburg JA 1996 Increased levels of $\mathrm{CD} 34^{+}$hemopoietic progenitor cells in atopic subjects. Am J Respir Cell Mol Biol 15:645-655

9. Upham JW, Hayes LM, Lundahl J, Sehmi R, Denburg JA 1999 Reduced expression of hemopoietic cytokine receptors on cord blood progenitor cells in neonates at risk for atopy. J Allergy Clin Immunol 104:370-375

10. Dunstan JA, Mori TA, Barden A, Beilin LJ, Taylor AL, Holt PG, Prescott SL 2003 Maternal fish oil supplementation in pregnancy reduces interleukin-13 levels in cord blood of infants at high risk of atopy. Clin Exp Allergy 33:442-448

11. Mori TA, Beilin LJ, Burke V, Morris J, Ritchie J 1997 Interactions between dietary fat, fish, and fish oils and their effects on platelet function in men at risk of cardiovascular disease. Arterioscler Thromb Vasc Biol 17:279-286

12. Ruiz RG, Kemeny DM, Price JF 1992 Higher risk of infantile atopic dermatitis from maternal atopy than from paternal atopy. Clin Exp Allergy 22:762-766

13. Martinez FD 1997 Maternal risk factors in asthma. Ciba Found Symp 206:233-239

14. Upham JW, Holt BJ, Baron-Hay MJ, Yabuhara A, Hales BJ, Thomas WR, Loh RK, O'Keeffe PT, Palmer L, Le Souef PN, Sly PD, Burton PR, Robinson BWS, Holt PG 1995 Inhalant allergen-specific T-cell reactivity is detectable in close to $100 \%$ of atopic and normal individuals: covert responses are unmasked by serum-free medium. Clin Exp Allergy 25:634-642

15. Macaubas C, Sly PD, Burton P, Tiller K, Yabuhara A, Holt BJ, Smallacombe TB, Kendall G, Jenmalm MC, Holt PG 1999 Regulation of T-helper cell responses to inhalant allergen during early childhood. Clin Exp Allergy 29:1223-1231

16. Ausiello CM, Lande R, Urbani F, la Sala A, Stefanelli P, Salmaso S, Mastrantonio P, Cassone A 1999 Cell-mediated immune responses in four-year-old children after primary immunization with acellular pertussis vaccines. Infect Immun 67:4064-4071

17. Denburg JA, Telizyn S, Messner H, Lim B, Jamal N, Ackerman SJ, Gleich GJ, Bienenstock J 1985 Heterogeneity of human peripheral blood eosinophil-type colonies: evidence for a common basophil-eosinophil progenitor. Blood 66:312-318

18. Sehmi R, Wood LJ, Watson R, Foley R, Hamid Q, O’Byrne PM, Denburg JA 1997 Allergen-induced increases in IL-5 receptor $\alpha$-subunit expression on bone marrowderived $\mathrm{CD} 34^{+}$cells from asthmatic subjects. A novel marker of progenitor cell commitment toward eosinophilic differentiation. J Clin Invest 100:2466-2475

19. Sutherland DR, Keating A, Nayar R, Anania S, Stewart AK 1994 Sensitive detection and enumeration of CD $34+$ cells in peripheral and cord blood by flow cytometry. Exp Hematol 10:1003-1010

20. Dunstan JA, Mori TA, Barden A, Beilin LJ, Taylor AL, Holt PG, Prescott SL 2004 Fish oil supplementation in pregnancy modifies neonatal allergen-specific immune responses and clinical outcomes in infants at high risk of atopy: a randomised, controlled trial. J Allergy Clin Immunol 112:1178-1184

21. Denburg JA, Richardson M, Telizyn S, Bienenstock J 1983 Basophil/mast cell precursors in human peripheral blood. Blood 61:775-780

22. Calder PC, Yaqoob P, Thies F, Wallace FA, Miles EA 2002 Fatty acids and lymphocyte functions. Br J Nutr 87:S31-S48

23. Hughes DA, Pinder AC 1997 N-3 polyunsaturated fatty acids modulate the expression of functionally associated molecules on human monocytes and inhibit antigenpresentation in vitro. Clin Exp Immunol 110:516-523

24. Fritsche KL, Byrge M, Feng C 1999 Dietary omega-3 polyunsaturated fatty acids from fish oil reduce interleukin-12 and interferon-gamma production in mice. Immunol Lett 65:167-173

25. Endres S, Meydani SN, Ghorbani R, Schindler R, Dinarello CA 1993 Dietary supplementation with $\mathrm{n}-3$ fatty acids suppresses interleukin-2 production and mononuclear cell proliferation. J Leukoc Biol 54:599-603

26. Meydani M, Natiello F, Goldin B, Free N, Woods M, Schaefer E, Blumberg JB, Gorbach SL 1991 Effect of long-term fish oil supplementation on vitamin E status and lipid peroxidation in women. J Nutr 121:484-491

27. Virella G, Fourspring K, Hyman B, Haskill-Stroud R, Long L, Virella I, La Via M, Gross AJ, Lopes-Virella M 1991 Immunosuppressive effects of fish oil in normal human volunteers: correlation with the in vitro effects of eicosapentanoic acid on human lymphocytes. Clin Immunol Immunopathol 61:161-176

28. Miles EA, Calder PC 1998 Modulation of immune function by dietary fatty acids. Proc Nutr Soc 57:277-292

29. Calder PC 2001 omega 3 polyunsaturated fatty acids, inflammation and immunity. World Rev Nutr Diet 88:109-116

30. Duchen K, Bjorksten B 2001 Polyunsaturated n-3 fatty acids and the development of atopic disease. Lipids 36:1033-1042

31. Braccioni F, Dorman SC, O'Byrne PM, Inman MD, Denburg JA, Parameswaran K, Baatjes AJ, Foley R, Gauvreau GM 2002 The effect of cysteinyl leukotrienes on growth of eosinophil progenitors from peripheral blood and bone marrow of atopic subjects. J Allergy Clin Immunol 110:96-101

32. Crawford L, Saito H, Inman MD, Denburg JA 2002 Effects of the cysteinyl leukotriene receptor antagonist, montelukast, on eosinophil differentiation in an experimental mouse model of allergic rhinitis. J Allergy Clin Immunol 109:S296

33. Prescott SL, Macaubas C, Smallacombe T, Holt BJ, Sly PD, Loh R, Holt PG 1998 Reciprocal age-related patterns of allergen-specific T-cell immunity in normal vs. atopic infants. Clin Exp Allergy 28:39-44

34. Prescott SL, Holt PG 1998 Abnormalities in cord blood mononuclear cytokine production as a predictor of later atopic disease in childhood. Clin Exp Allergy 28:1313-1316 